All letters are subject to editing and may be shortened. Letters should be sent to the BJGP office by e-mail in the first instance, addressed to journal@rcgp.org.uk (please include your postal address). Alternatively, they may be sent by post as an MS Word or plain text version on CD or DVD. We regret that we cannot notify authors regarding publication. Letters not published in the Journal may be posted online on our Discussion Forum. For instructions please visit: http://www.rcgp.org.uk/bjgp-discuss

\section{Future recruitment of GPs to deprived areas}

It was interesting to read Jacky Hayden's editorial where she said, 'future recruitment of GPs to deprived areas will need sustained action'. 'S She is correct, but I am afraid the answer is partly to do with the ' $m$ ' word: 'money'. I am painfully aware that medical royal colleges, because of their charitable status, are reluctant to go near 'pay and rations' issues; that is the job of the British Medical Association. However, when pay and rations get to the point that patient care and medical standards are at risk of starting to fall, then maybe medical royal colleges should say something?

It is already in the public domain that a GP with just a General Medical Services contract earns about $£ 20000$ per annum less than a dispensing GP for the same sort of list size, who, by definition in England, are all in rural practices. Working where I do, in an island of deprivation in the centre of an otherwise relatively affluent central southern England, I see a lot of colleagues struggling with an unacceptably high workload for a below average remuneration.

Why is the workload high? Well, we all know that deprivation is linked to pathology, with the Quality and Outcomes Framework (QOF) really not covering the issue properly as we have a high number of defaulters, who cannot always be exception reported (I even hear stories of exception reporting being forbidden in the future!). Add to that the large number of social problems that somehow end up at the GP's door yet attract no QOF points, such as long-term sickness certification, endless requests for letters for appeals against refusal of benefit, letters regarding housing problems, substance abuse issues, the general 'GANFYD' (get a note from your doctor) society we live in, and one can see why the workload in deprived areas is high and demanding. In Germany, where primary care doctors are paid per consultation, the problem is getting GPs to work in the country areas, as the rural, relatively healthy, population go to the GP less often and income therefore falls.

I am writing this on a Sunday, knowing that already I have 20 patients booked in for tomorrow morning, and 16 for the evening. I shall probably do three visits, and perhaps handle about 16-20 telephone consultations in the day, as well as deal with the usual lab results and scanned letters. I am sure that is a familiar scenario to many urban GPs. For my fourand-a-bit days of work a week, I shall be earning a take home pay before tax of about $£ 70000$ this year. A lot less than the Daily Mail headlines. I stay where I am because I work with a great bunch of doctors and staff, and because it currently suits me, but as I get nearer to retirement, the thought of leaving the NHS and going to do long locums in Australia for a couple of years becomes more and more attractive; especially with the current exchange rates. Why would any newly qualified GP want to come and work in an urban environment if they can get a post in a rural/semi-rural practice, or a post in a relatively affluent town?

I am aware that rural communities have their own problems and some degree of deprivation, but where I live just north of Southampton, 'deprived' means you drive a 6-year-old Mondeo rather than a Mercedes. 'Jealous, moi?' No - perhaps just a bit jaded, and fed up at hearing, from some colleagues who should know better, terms like, 'failing urban practices' as a fairly broad-brush term.
John Glasspool,

GP, Victor Street Surgery, Shirley,

Southampton SO15 5SY.

E-mail: john.glasspool@gmail.com

\section{REFERENCE}

1. Hayden J. Strengthening general practice in deprived localities. Br J Gen Pract 2010; 60(580): 797-798.

DOI: 10.3399/bjgp11X549027

\section{Selecting GP speciality trainees: squaring the circle?}

Irish and Patterson's discussion paper reviewed the current pathway for selecting GP speciality trainees. They ask how it can be improved.'

Despite Mencken's caution that 'for every complex problem there is an answer that is clear, simple, and wrong', ${ }^{2}$ maybe there is an easier way.

The current structure (The National Recruitment Office for GP Training), the process (a single standardised recruitment system), and the specific outcome (successful completion of GP speciality training), coupled with continuing attempts to improve the process could make the journey to becoming a GP less of a maze and more a motorway to success.

The ideal selection outcome is that the recruited GP subsequently provides high quality care throughout a 30-year career. An optimal outcome may be that the GP provides high quality care for 5 years and then passes revalidation. The minimum outcome is that the GP passes the MRCGP licensure examination by the end of 3 years of training. However, low pass rates in the Clinical Skills Assessment (CSA) module of the MRCGP examination suggest that either the selection process is 
flawed, or that the CSA is not a reliable, fair, and valid test. The flaw in selection may be that it is impossible to reconcile the need for the recruitment process to fill all the training posts every year, and ensure that all these recruits pass the MRCGP examination within their 3 years of training. Any worries that the MRCGP examination is not a good test of competence needs to be addressed by the Royal College of General Practitioners (RCGP).

Although the RCGP has always wanted a longer training scheme, the recruitment process needs to select candidates who are likely to pass the MRCGP exam within their 3 years of training. The Menckendefying improvement may be to link their selection to the results of taking real or mock modules of the MRCGP examination. These modules could be taken online at a convenient Applied Knowledge Test examination centre, remotely by reviewing the candidates' existing ePortfolios including work-place based assessments, and by a CSA at nearby GP-training practices. The candidates could pay a fee to take these assessment modules. Only those candidates with qualifying scores would be eligible to apply for GP training.

The results of these tests could inform the training of recruits to improve their chances of success in the MRCGP exam. Weaker candidates may need a few attempts over a couple of years to qualify for GP training. Perhaps the best of these weaker candidates could be offered any unfilled training posts on an ad hoc basis, but they would not be in the 3-year GP training scheme.

Educators and learners may be reluctant to concentrate their efforts on passing a test, but the RCGP - GP curriculum statements already point in this direction. The RCGP regularly updates a curriculum that describes what a GP needs to be able to do to work in general practice for the first 5 years and conducts a membership examination that should be a reliable, fair, and valid test of that ability. After the first 5 years, the RCGP's (and General Medical Council's) regular revalidation should ensure that GPs have the competencies to practice for the rest of their careers.
Mencken also advised 'a judge is a law student who marks his own examination papers'. ${ }^{2}$ This may describe the continuing difference between our confidence and competence in our assessment of the ability of others.

\section{Terry Kemple,}

Horfield Health Centre, Lockleaze Road, Horfield, Bristol BS7 9RR.

E-mail: tk@elpmek.demon.co.uk

\section{REFERENCES}

1. Irish B, Patterson F. Selecting general practice speciality trainees: where next? Br J Gen Pract 2010; 60(580): 849-852.

2. Mencken HL. Quotes. Quotes Museum. http://www.quotes-museum.com/quote/59695 (accessed 1 Dec 2010).

DOI: 10.3399/bjgp11X549036

\section{Jumping (or being pushed) from maternity care?}

I read with interest the recent editorial entitled 'Jumping (or being pushed) from maternity care'. ${ }^{1}$ The overall conclusion that GPs should still play a role in maternity care is something that is echoed by the findings of a recent study I undertook following the Kings Fund report entitled, 'The role of GPs in maternity care - what does the future hold?'. ${ }^{2}$

I issued a postal questionnaire to $50 \%$ of GPs $(n=338)$ in the Leeds PCT, in the north of England; $65 \%(n=200)$ replied.

The aim was to elicit the views of GPs on their role in maternity care. Of the GPs, $61 \%(n=134)$ 'disagreed' with the statement that they had a major role in the care of a pregnant woman, $11 \%(n=24)$ 'strongly disagreed'.

The editorial by Jewell stated there is a trend to omit obstetric content in postgraduate GP training programmes, ${ }^{1}$ a finding that was confirmed in my study. Forty per cent $(n=88)$ of GPs felt that they do not have adequate current knowledge of maternity care and many stated that they have become deskilled as maternity care has been taken over by midwives; $71 \%(n=145)$ felt that the best way to gain up-to-date knowledge would be to attend a postgraduate course; and $17 \%(n=35)$ suggested an e-learning scheme, as this would allow them to work through the programme at convenient times, and they would gain certification on completion.

In his editorial Jewell stated that 'even if midwives assume responsibility for all routine care, there will always remain the possibility of GPs being presented with obstetric emergencies'. 'Many GPs who replied felt that it was important that they were still involved in maternity care, so they are able to recognise difficult cases and deal with them adequately.

This is an important topic and I would strongly recommend a larger study to see if my findings can be duplicated on a national scale.

\section{James O'Donovan,}

3 Creskeld Crescent, Bramhope,

Leeds LS16 9EH.

E-mail: james.o'donovan@ncl.ac.uk

\section{REFERENCES}

1. Jewell D. Jumping (or being pushed) from maternity care. Br J Gen Pract 2010; 60(580): 799-800.

2. Smith A, Shakespeare J, Dixon A. The role of GPs in maternity care - what does the future hold? London: The Kings Fund, 2010. http://www.kingsfund.org.uk/ document.rm?id=8734 (accessed 29 Dec 2010).

DOI: 10.3399/bjgp11X549045

\section{Community orientation in education}

Higher education is already feeling the effects of funding reductions, and medical education is likely to be squeezed too. It is crucial that medical educators demonstrate the quality and value of graduates and show that 6 years of extensive experience for young people in the highest academic bracket produces a workforce of considerable and unique value.

Rees and Stephenson write ${ }^{1}$ that there is a continuing move for more health care to be delivered in the community, requiring more qualified doctors working in the area, leading to an increase in the proportion of the graduates training for 